\title{
Practical and Emotional Problems Reported by Users of a Self-guided Digital Problem-solving Intervention During the COVID-19 Pandemic: Content Analysis
}

\author{
Amira Hentati ${ }^{1,2}$, MSci; Erik Forsell ${ }^{1}, \mathrm{PhD}$; Brjánn Ljótsson ${ }^{2}, \mathrm{PhD}$; Martin Kraepelien ${ }^{1,2}, \mathrm{PhD}$ \\ ${ }^{1}$ Centre for Psychiatry Research, Department of Clinical Neuroscience, Karolinska Institutet \& Stockholm Health Care Services, Region Stockholm, \\ Stockholm, Sweden \\ ${ }^{2}$ Division of Psychology, Department of Clinical Neuroscience, Karolinska Institutet, Stockholm, Sweden
}

\section{Corresponding Author:}

Amira Hentati, MSci

Centre for Psychiatry Research

Department of Clinical Neuroscience

Karolinska Institutet \& Stockholm Health Care Services, Region Stockholm

Norra Stationsgatan 69

Stockholm, 11364

Sweden

Phone: 46704411425

Email: amira.hentati@ki.se

\section{Abstract}

Background: To better direct assessments and interventions toward the general population during both the ongoing COVID-19 pandemic and future crises with societal restrictions, data on the types of practical and emotional problems that people are experiencing are needed.

Objective: The aim of this study was to examine the types of practical and emotional problems that the general population is experiencing during the COVID-19 pandemic and to construct an empirically derived inventory based on the findings.

Methods: A total of 396 participants, recruited among members of the general public in Sweden who were experiencing practical and/or emotional problems during the pandemic, accessed a self-guided digital problem-solving intervention for a period of 1 week to report and solve the problems they experienced. Prior to accessing the intervention, the participants completed a short self-assessment regarding symptoms of depression and anxiety. Content analysis was used to account for the types of problems participants reported. A set of items for an inventory was later proposed based on the problem categories derived from the analysis.

Results: A majority of participants had clinically relevant symptoms of either depression or anxiety. The problems reported were categorized as 13 distinct types of problems. The most common problem was difficulty managing daily activities. Based on the categories, a 13-item inventory was proposed.

Conclusions: The 13 types of problems, and the proposed inventory, could be valuable when composing assessments and interventions for the general population during the ongoing pandemic or similar crises with societal restrictions. The most common problem was of a practical nature, indicating the importance of including examples of such problems within assessments and interventions.

Trial Registration: ClinicalTrials.gov NCT04677270; https://clinicaltrials.gov/ct2/show/NCT04677270

(JMIR Form Res 2021;5(10):e31722) doi: 10.2196/31722

\section{KEYWORDS}

digital intervention; COVID-19; problem-solving; self-guided intervention; content analysis; public health; mental health; depression; anxiety; pandemic 


\section{Introduction}

\section{Background}

The COVID-19 pandemic is considered a threat to the mental well-being of the general public and may increase the suicide risk for some people [1,2]. This threat consists of both emotional problems, such as anxiety, loneliness, and low mood [2,3], and practical problems, such as not being able to work remotely or to travel as before the pandemic [4,5].

Population-level efforts aiming to prevent negative mental health consequences have been called for since the first months of the COVID-19 pandemic [1]. Furthermore, remotely implementable digital interventions for treatment and prevention have been seen as critical to achieve the scalability necessary to have an impact on the health of the general public [6]. An example of a successful population-level effort during the COVID-19 pandemic is described in a previous study in which an existing intervention for extensive worry was adapted to COVID-19-related worry, transformed into a self-guided format [7], and later implemented in the Swedish regular health care system. However, because worry is only one possible problem experienced by the general population during the COVID-19 pandemic [8], there is a need to assess what types of practical and emotional problems the general population is experiencing. This could facilitate the direction of assessments and interventions toward the general public both during the ongoing pandemic and in future similar crises.

Problem-solving therapy is a well-examined intervention that was originally constructed for major depression, targeting the ability to solve problems [9]. Moreover, the ability to solve problems has been highlighted as one of several protective factors for individuals in the general population affected by the COVID-19 pandemic when considering societal suicide prevention [10]. A problem-solving intervention could thus be a suitable intervention for the general public experiencing practical or emotional problems during the ongoing pandemic. Ideally, it should be easy to gain access to such an intervention, and the intervention should be self-guided to facilitate scalability. An open access and self-guided internet-based psychological support intervention (PATH), which includes problem-solving as well as conflict management and stress management, has been examined with regard to participants' input to the program during the COVID-19 pandemic [11]. In that study, conflicts with others, worry, and difficulties concentrating stood out as the most common types of problems during the pandemic.

\section{Aim}

The aim of this study was to examine the types of practical and emotional problems that the Swedish help-seeking population is experiencing during the COVID-19 pandemic. An additional aim was to construct an empirically derived inventory to facilitate the assessment of problems and direction of interventions in the general population during the ongoing pandemic or similar crises with societal restrictions.

\section{Methods}

\section{Setting and Study Design}

This study was part of a project aiming to investigate treatment engagement with a self-guided digital problem-solving intervention between two different user interfaces. The results concerning the effect of the user interfaces on treatment engagement have been presented in a previous paper [12]. In this paper, the focus lies on the types of practical and emotional problems that the general help-seeking population in Sweden reported experiencing during the COVID-19 pandemic when using a self-guided digital problem-solving intervention. The study was approved by the Swedish national ethical review board (ID 2020-02739), and although the article does not report results of a health care intervention, the study was retrospectively registered on ClinicalTrials.gov (ID: NCT04677270, 2020-12-21).

\section{Participants and Recruitment}

The target population was the general help-seeking population in Sweden who were experiencing practical and/or emotional problems during the COVID-19 pandemic. Participants were recruited nationwide in Sweden through advertisements on social media during a period of 6 weeks, between August 26 and October 6, 2020. Inclusion criteria were (1) age of 16 years or older, and (2) self-reported practical and/or emotional problems experienced during the COVID-19 pandemic. The second criterion was assessed through a question asking if participants experienced practical problems, emotional problems, practical and emotional problems, or no problems. No further definition of these problems was given at this stage of assessment.

\section{Procedures}

To register for the study, participants completed a digital self-assessment on a secure digital platform. Written informed consent was digitally provided by all participants. Of the 399 individuals who registered for the study, only 2 persons were excluded from participating, owing to not experiencing problems (ie, the second inclusion criterion was not met). Furthermore, 1 person withdrew consent for participation. A total of 396 participants were thus included, and they accessed a self-guided digital problem-solving intervention for a period of one week to report and solve problems they experienced. The study flowchart is shown in Figure 1. 
Figure 1. Flowchart of the selection of study participants.

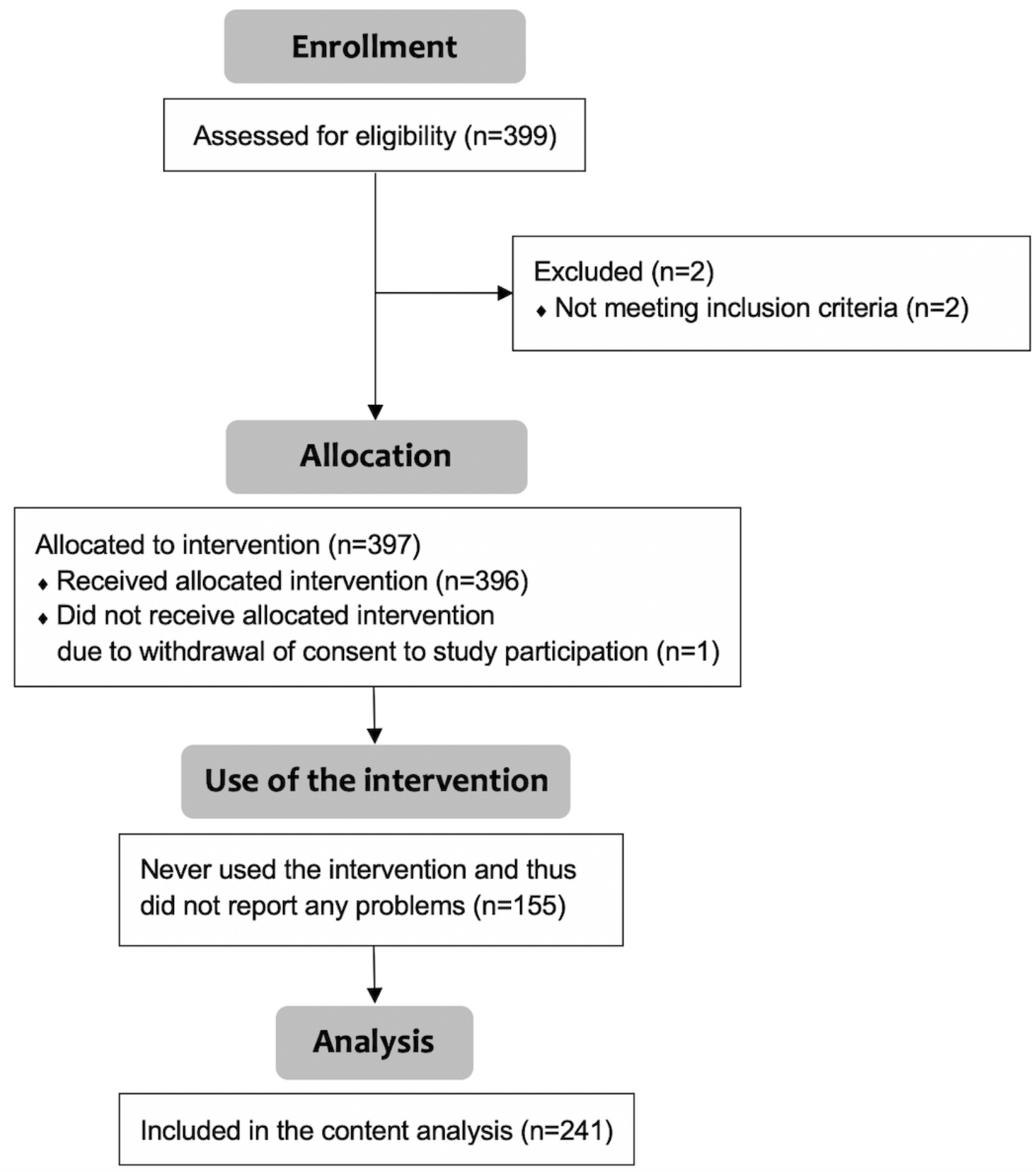

\section{Intervention}

A self-guided digital problem-solving intervention adapted to the COVID-19 pandemic was created for the study. An already existing digital problem-solving intervention, previously used as a component in a 12-week multi-component internet-delivered cognitive behavioral therapy program for individuals with major depression in Swedish regular health care [13], was used as a template and adapted for self-guidance.

The problem-solving intervention comprised psychoeducational texts and rationale, examples of problems and suggestions of solutions, pictures, instructions, and problem-solving exercises. The exercises consisted of steps where participants were able to describe and choose to work with one problem at a time; set a goal; make a list of possible solutions to the problem, including pros and cons; choose what solutions to try and plan how and when to try them out; and then evaluate the solutions and reflect on possible lessons learned. All material within the intervention was in Swedish and was adapted to the pandemic situation. Participants could read texts about four fictive users having the following problems: health-related worry, stress because of their financial situation, loneliness, and problems with household activities. In total, the intervention consisted of a single module of approximately 4800 words. The length of the intervention was 1 week, because the current study only intended to examine types of problems and platform use (data presented in [12]) and not problem-solving as a clinical intervention. The intervention could be accessed on a secure digital platform via a computer or mobile device connected to the internet.

\section{Measurements}

When registering for the study, participants completed a digital assessment comprising questions on demographics and whether they experienced problems during the COVID-19 pandemic. 
Participants also completed two self-assessed short scales, the Patient Health Questionnaire-2 (PHQ-2) [14] and Generalized Anxiety Disorder-2 (GAD-2) [15], measuring symptoms of depression and anxiety, respectively. These scales were administered to assess the proportion of participants with a possible clinical symptom burden, but they were not used either for inclusion or as an outcome measure.

\section{Data Analysis}

Content analysis [16] was used to code all participants' problem-solving attempts that were reported and saved within the digital platform as well as to create categories of problems based on these. All problem-solving attempts were entered in text on the digital treatment platform. Thus, transcription of data was not needed.

The step-by-step categorization of data started with defining each problem-solving attempt as the unit of analysis [17]. A problem-solving attempt was registered every time a participant completed the first step of the problem-solving exercises, which was to define the problem. Thus, a problem-solving attempt did not necessarily constitute a complete problem-solving exercise. To create categories for the content analysis, 25 participants were selected randomly for initial coding. Three of the authors, $\mathrm{AH}, \mathrm{EF}$, and $\mathrm{MK}$, coded these participants jointly and created the coding instructions as well as the categories with consensus. Then, another 25 randomly selected participants were independently coded by the three coders, using the instructions and categories created. The interrater agreement between the coders was substantial [18] (Cohen $\kappa=0.66-0.76$ ). After checking that the interrater reliability was acceptable, disagreements were discussed until a consensus was reached. Afterward, the remaining 346 participants were divided between the three coders, and their problem-solving attempts were coded using the identified categories. Any uncertain categorizations were discussed with all coders. Each category was defined in turn as mainly either a practical or emotional problem.
The categorization of reported problem-solving attempts was later used in a quantitative description of the content [17]: namely, the number of problem-solving attempts that belonged to each category, as well as the number of the participants who had solved at least one problem that belonged to each category. Furthermore, to ensure that the data were not skewed by a few active participants, the use of the intervention was quantified by the percentage of participants using the intervention at least once, as well as the average number of problem-solving attempts completed during the week of access. Lastly, based on the problem categories derived from the analysis, a set of items for an inventory was proposed.

\section{Results}

A majority of participants were women, were university educated, and had clinically relevant symptoms of either depression or anxiety. Table 1 shows the complete sample characteristics.

A majority of participants used the problem-solving intervention at least once during the week of access. Table 2 shows details on the use of the intervention.

The problems reported within the intervention by the participants who used the intervention at least once were categorized into 13 distinct types of problems, which can be found in Table 3 . The 3 most frequent categories of problems were of a practical nature, such as difficulties initiating daily activities, problems or frustration regarding one's work and/or study situation, and problems or frustration with public health guidelines or the pandemic situation in general.

Based on the 13 distinct types of problems derived from the content analysis (see Table 3), the items shown in Textbox 1 are proposed as an inventory of practical and emotional problems during the COVID-19 pandemic. 
Table 1. Sample characteristics $(\mathrm{N}=396)$.

\begin{tabular}{|c|c|}
\hline Variable & Value \\
\hline Female gender, n (\%) & $352(88.9)$ \\
\hline \multicolumn{2}{|l|}{ Age (years) } \\
\hline Mean (SD) & $40(13)$ \\
\hline Range & $17-79$ \\
\hline In a relationship, $\mathrm{n}(\%)$ & $246(62.1)$ \\
\hline \multicolumn{2}{|l|}{ Occupational status, n (\%) } \\
\hline Employed full-time & $200(50.5)$ \\
\hline Employed part-time & $41(10.4)$ \\
\hline Student & $68(17.2)$ \\
\hline Parental leave & $7(1.8)$ \\
\hline Unemployed & $34(8.6)$ \\
\hline Long-term sick leave & $21(5.3)$ \\
\hline Retired & $25(6.3)$ \\
\hline \multicolumn{2}{|l|}{ Education, $\mathbf{n}(\%)$} \\
\hline Primary school & $7(1.8)$ \\
\hline Secondary school & $78(19.7)$ \\
\hline University & $311(78.6)$ \\
\hline Possible major depression (PHQ-2 ${ }^{\mathrm{a}}$ score $\geq 3$ ), n (\%) & $235(59.3)$ \\
\hline Possible generalized anxiety (GAD- $2^{b}$ score $\geq 3$ ), n (\%) & $236(59.6)$ \\
\hline Concurrent possible depression and anxiety, n (\%) & $180(44.5)$ \\
\hline Either possible depression, anxiety, or both, n (\%) & $291(73.5)$ \\
\hline
\end{tabular}

${ }^{\mathrm{a} P H Q-2: ~ P a t i e n t ~ H e a l t h ~ Q u e s t i o n n a i r e-2 . ~}$

${ }^{\mathrm{b}}$ GAD-2: Generalized Anxiety Disorder-2.

Table 2. Use of the problem-solving intervention $(\mathrm{N}=396)$.

\begin{tabular}{ll}
\hline Variable & Value \\
\hline Used the problem-solving intervention at least once, $\mathrm{n}(\%)$ & $241(60.9)$ \\
Problem-solving attempts per participant, mean (SD) & $1.13(1.44)$ \\
\hline
\end{tabular}


Table 3. Types of problems identified from the content analysis.

\begin{tabular}{|c|c|c|c|c|c|}
\hline Problem type & $\begin{array}{l}\text { Problem cate- } \\
\text { gory }\end{array}$ & $\begin{array}{l}\text { Number of partici- } \\
\text { pants with problem } \\
\text { (\% of number of } \\
\text { participants who } \\
\text { used the interven- } \\
\text { tion at least once, } \\
\mathrm{N}=241 \text { ) }\end{array}$ & $\begin{array}{l}\text { Number of } \\
\text { problems ( } \% \text { of } \\
\text { total number of } \\
\text { reported prob- } \\
\text { lems, } \mathrm{N}=446 \text { ) }\end{array}$ & Definition & Examples \\
\hline Daily activities & Practical & $51(21.2)$ & $59(13.2)$ & $\begin{array}{l}\text { Difficulties initiating daily } \\
\text { activities, staying motivated, } \\
\text { or maintaining focus }\end{array}$ & $\begin{array}{l}\text { - Not getting household activities done } \\
\text { - Spending too much time on social } \\
\text { media }\end{array}$ \\
\hline Work and study & Practical & $46(19.1)$ & $51(11.4)$ & $\begin{array}{l}\text { Problems or frustration re- } \\
\text { garding work and/or study } \\
\text { situation }\end{array}$ & $\begin{array}{l}\text { - Working at home with children } \\
\text { - Struggling with digital work or studies }\end{array}$ \\
\hline Health behaviors & Practical & $40(16.6)$ & $44(9.9)$ & $\begin{array}{l}\text { Difficulties maintaining } \\
\text { health promoting behaviors } \\
\text { such as physical activity, } \\
\text { satisfactory sleep patterns, } \\
\text { or active recovery }\end{array}$ & $\begin{array}{l}\text { - Getting less physical exercise than } \\
\text { usual } \\
\text { - Having trouble falling asleep }\end{array}$ \\
\hline $\begin{array}{l}\text { Family and relation- } \\
\text { ship }\end{array}$ & Emotional & $37(15.4)$ & $40(9)$ & $\begin{array}{l}\text { Problems related to relation- } \\
\text { ships, including family, } \\
\text { friends, or significant other }\end{array}$ & $\begin{array}{l}\text { - } \quad \text { Feeling unhappy in a relationship } \\
\text { - Finding it difficult to establish new } \\
\text { relationships }\end{array}$ \\
\hline Health anxiety & Emotional & $35(14.5)$ & $36(8.1)$ & $\begin{array}{l}\text { Affected emotionally by } \\
\text { health fears or worry regard- } \\
\text { ing self or others }\end{array}$ & $\begin{array}{l}\text { Worrying about being infected with } \\
\text { COVID-19 } \\
\text { Worrying that relatives or friends will } \\
\text { become ill with COVID-19 }\end{array}$ \\
\hline $\begin{array}{l}\text { Pandemic guide- } \\
\text { lines }\end{array}$ & Practical & $31(12.9)$ & $45(10.1)$ & $\begin{array}{l}\text { Problems or frustration with } \\
\text { public health guidelines or } \\
\text { the pandemic situation in } \\
\text { general }\end{array}$ & $\begin{array}{l}\text { - Being bound to home as soon as you } \\
\text { experience the sightliest signs of } \\
\text { symptoms of COVID-19 } \\
\text { - Feeling frustrated at others not follow- } \\
\text { ing the pandemic guidelines }\end{array}$ \\
\hline $\begin{array}{l}\text { Non-health-related } \\
\text { anxiety or stress }\end{array}$ & Emotional & $30(12.4)$ & $35(7.8)$ & $\begin{array}{l}\text { Affected emotionally by } \\
\text { non-health-related anxiety } \\
\text { or stress-related problems }\end{array}$ & $\begin{array}{l}\text { - Experiencing social anxiety or general- } \\
\text { ized anxiety } \\
\text { - Feeling overwhelmed }\end{array}$ \\
\hline Financial issues & Practical & $26(10.8)$ & $30(6.7)$ & Financial problems or fears & $\begin{array}{l}\text { - Experiencing fear of losing your job } \\
\text { - Experiencing loss of income }\end{array}$ \\
\hline Loneliness & Emotional & $22(9.1)$ & $22(4.9)$ & $\begin{array}{l}\text { Affected emotionally by } \\
\text { loneliness }\end{array}$ & $\begin{array}{l}\text { - Negatively affected by having had less } \\
\text { contact with family or friends } \\
\text { - Experiencing social isolation }\end{array}$ \\
\hline Low mood & Emotional & $20(8.3)$ & $21(4.7)$ & $\begin{array}{l}\text { Low mood or feelings of } \\
\text { meaninglessness }\end{array}$ & $\begin{array}{l}\text { - Feeling sad most of the time } \\
\text { - Experiencing apathy }\end{array}$ \\
\hline $\begin{array}{l}\text { Changes in emo- } \\
\text { tional state apart } \\
\text { from anxiety and } \\
\text { low mood }\end{array}$ & Emotional & $19(7.9)$ & $22(4.9)$ & $\begin{array}{l}\text { Emotional challenges other } \\
\text { than anxiety or low mood }\end{array}$ & $\begin{array}{ll}\text { - } & \text { Feeling angry } \\
\text { - } & \text { Experiencing low self-esteem }\end{array}$ \\
\hline Health issues & Practical & $19(7.9)$ & $23(5.2)$ & $\begin{array}{l}\text { Health issues related to } \\
\text { COVID-19 or other illness } \\
\text { regarding self or others }\end{array}$ & $\begin{array}{l}\text { Experiencing difficult symptoms of } \\
\text { COVID-19 or other illness } \\
\text { - Having a relative or friend with health } \\
\text { issues }\end{array}$ \\
\hline Weight and eating & Practical & $18(7.5)$ & $18(4)$ & $\begin{array}{l}\text { Problems related to weight } \\
\text { or eating }\end{array}$ & $\begin{array}{l}\text { Experiencing unintentional weight } \\
\text { change } \\
\text { - Struggling with binge eating }\end{array}$ \\
\hline
\end{tabular}


Textbox 1. Proposed inventory of practical and emotional problems during a crisis with societal restrictions.

Practical problems: do you experience...

- Difficulties initiating daily activities, staying motivated or maintaining focus? Examples of these difficulties include not getting household activities done, or spending too much time on social media.

- Problems or frustration regarding your work and/or study situation? Examples of these problems include working at home with children, or struggling with digital work or studies.

- Difficulties maintaining health promoting behaviors such as physical activity, satisfactory sleep patterns, or active recovery? Examples of these difficulties include getting less physical exercise than usual, or having trouble falling asleep.

- Problems or frustration with public health guidelines or the pandemic situation in general? Examples of these problems include being bound to home as soon as you experience the sightliest signs of symptoms of COVID-19, or feeling frustrated at others not following the pandemic guidelines.

- $\quad$ Financial problems or fears? Examples of these problems include experiencing fear of losing your job or of losing income.

- Health issues related to COVID-19 or other illness regarding self or others? Examples of these problems include experiencing difficult symptoms of COVID-19 or other illness, or having a relative or friend with health issues.

- Problems related to weight or eating? Examples of these problems include experiencing unintentional weight change, or struggling with binge eating.

Emotional problems: do you experience...

- Problems related to relationships, including with your family, friends, or significant other? Examples of these problems include feeling unhappy in a relationship, or finding it difficult to establish new relationships.

- Being affected emotionally by health fears or worry regarding yourself or others? Examples of these difficulties include fearing or worrying about being infected with COVID-19, or worrying that relatives or friends will become ill with COVID-19.

- Being affected emotionally by non-health-related anxiety or stress? Examples of these difficulties include experiencing social anxiety or generalized anxiety, or feeling overwhelmed.

- Being affected emotionally by loneliness? Examples of these difficulties include being negatively affected by having had less contact with family or friends, or experiencing social isolation.

- A low mood or feelings of meaninglessness? Examples of these problems include feeling sad most of the time, or experiencing apathy.

- Emotional challenges other than anxiety or low mood? Examples of these difficulties include feeling angry, or experiencing low self-esteem.

\section{Discussion}

\section{Principal Results}

In this study, COVID-19-related practical and emotional problems experienced by the Swedish help-seeking population were examined during the use of a self-guided digital problem-solving intervention. Content analysis was used to investigate the types of problems reported within the intervention.

The participants reported 13 different distinct types of problems. Practical problems, such as managing one's daily life and work situation, were most frequently reported, while loneliness, low mood, and other emotional difficulties were less common. The dominance of practical problems may have been due to participants preferring to use the digital problem-solving intervention to generate solutions to practical problems rather than emotional problems. However, it may also have to do with practical problems actually being the predominant problem type experienced by participants in this study. Additionally, it has been reported that the COVID-19 pandemic has had a vital impact on people's practical work situations [19]; societal restrictions have also led to great challenges in managing work-family balance, with sometimes minor support [20,21]. It should be further noted that the short scales PHQ-2 and GAD-2, which were used to assess the proportions of participants with possible major depression and anxiety, respectively, are probably quite sensitive to symptoms when used at the stage of screening [14]. This could help explain the high prevalence of possible clinical symptom burden among the participants, despite the fact that practical problems were more commonly reported than emotional ones.

In a previous study, COVID-19-related worry was highlighted as a target for a self-guided digital intervention [7]. Among the participants in the current study, health anxiety was reported, but it was not as common as problems of a more practical nature. This highlights the need to target a broad range of problems during a crisis involving a disease, including problems of a practical nature, as a complement to health-related worry.

The relatively low frequency of mood-related problems and feelings of loneliness may need to be interpreted within the context of the study being conducted in Sweden. Sweden has, unlike most other countries, not imposed mandatory lockdown during the COVID-19 pandemic. This may have impacted the mental well-being of the inhabitants. However, owing to voluntary restrictions recommended by the Swedish government during the pandemic, Sweden has had similar societal consequences, such as economic damage, to those of countries in lockdown [22]. As the results show, a number of people reported financial problems. These results can further be compared to the problems entered during the pandemic in the 
previously mentioned PATH program, which was based in the United States [12]. In that study, the common types of problems reported were similar to those in the current study, except for a greater emphasis on interpersonal conflicts, possibly due to the separate conflict management module in the PATH program. In most cases, these types of problems would fall into the category of problems related to relationships in the proposed inventory of the current study.

Although vaccination for COVID-19 has begun worldwide, it is still not clear whether some problems, both societal and health-related, that have arisen during the pandemic will persist for some time $[23,24]$. We believe that the inventory proposed in this paper of practical and emotional problems during a crisis with societal restrictions could therefore be of value not only during the still ongoing pandemic but also possibly in the near future. We propose that the inventory can act as a guide when constructing both assessments and interventions related to COVID-19 problems while also providing some public health information concerning the pandemic and its consequences.

Because most items in the proposed inventory are not specific to COVID-19, the inventory may also provide helpful guidance in future similar crises. However, it is not certain that all the items will be relevant in a future crisis with societal restrictions. Health anxiety, which was reported in this study, is an example of a type of problem that is more likely to occur during crises involving a disease. However, most other items derived from the content analysis fit into a crisis with societal restrictions whether or not a disease is involved.

Based on the fact that recruitment to the study was rapid, during a relatively short period of time, we interpreted the interest in gaining access to a problem-solving intervention as high. This reflects an apparent desire for interventions of this kind. We believe that this has practical implications, as the results from this study can be used to adapt and possibly improve similar interventions, both during the still-ongoing pandemic as well as for possible persisting problems that arose due to the pandemic.

When providing digital interventions in a self-guided format, there is a risk of low adherence and low use. This was exemplified in a previous Swedish adaptation of a self-guided intervention for mental health problems [25]. We believe that one of the strengths of the current study is that a majority of participants used the digital intervention and hence contributed to the generalizability of the results.

\section{Limitations}

There are some limitations to this study that need to be acknowledged. First, the sample predominantly consisted of university-educated women, which impacts the generalizability of the results. Second, participants were recruited through advertisements on social media. We are not sure if the results or sample would have differed if additional recruitment methods would have been used. Third, we have no available data concerning problems reported by the current population before the COVID-19 pandemic, making it difficult to discern the impact of the pandemic on the problems reported. Fourth and last, the problem-solving intervention constructed for individuals with major depression that was used as a template for the development of the digital intervention used in the current study is intended to be used over several weeks [13]. In the current study, access to the intervention was limited to a period of 1 week. It is unclear whether a longer period of access to the intervention would have resulted in participants reporting additional types of problems.

\section{Future Research}

For future studies, we recommend that the inventory suggested within this paper be evaluated with regard to psychometric properties.

\section{Conclusions}

The reported problems of participants during the COVID-19 pandemic in this study fell into 13 distinct categories of problems. These can serve as targets of interventions or be of help when screening for problems in the general population during the ongoing pandemic or in future similar crises. The most frequently reported types of problems were of a practical nature, indicating the importance of giving examples of practical problems within both interventions and assessments.

\section{Acknowledgments}

This study was funded by the Government of Sweden, Ministry of Health and Social Affairs, and it used the BASS platform from the eHealth Core Facility at Karolinska Institutet, which is supported by the Strategic Research Area Healthcare Science (SFO-V). We wish to thank professor Nils Lindefors for initiating and supporting the project.

\section{Authors' Contributions}

AH and MK performed the literature search and drafted the manuscript. AH, EF, and MK performed the content analysis. All authors, AH, EF, BL, and MK, were involved in the study design and the acquisition of data; contributed to the statistical analysis and interpretation of the data; and have read, revised, and approved the manuscript. AH, EF, and MK verify the accuracy of the underlying data.

\section{Conflicts of Interest}

$\mathrm{BL}$ is a shareholder of DahliaQomit AB, a company specializing in online psychiatric symptom assessment, and Hedman-Lagerlöf och Ljótsson psykologi AB, a company that licenses cognitive behavior therapy manuals. AH, EF, and MK do not have any competing interests. 


\section{References}

1. Galea S, Merchant RM, Lurie N. The mental health consequences of COVID-19 and physical distancing: the need for prevention and early intervention. JAMA Intern Med 2020 Jun 01;180(6):817-818. [doi: 10.1001/jamainternmed.2020.1562] [Medline: 32275292]

2. Moutier C. Suicide prevention in the COVID-19 era: transforming threat into opportunity. JAMA Psychiatry 2020 Oct 16;78(4):433. [doi: 10.1001/jamapsychiatry.2020.3746] [Medline: 33064124]

3. Canet-Juric L, Andrés ML, Del Valle M, López-Morales H, Poó F, Galli JI, et al. A longitudinal study on the emotional impact cause by the COVID-19 pandemic quarantine on general population. Front Psychol 2020 Sep 18;11:565688 [FREE Full text] [doi: 10.3389/fpsyg.2020.565688] [Medline: 33071893]

4. Bartik A, Cullen Z, Glaeser E, Luca M, Stanton C. What Jobs Are Being Done at Home During the COVID-19 Crisis? Evidence From Firm-Level Surveys. National Bureau of Economic Research. 2020 Jun. URL: https://www.nber.org/system/ files/working papers/w27422/w27422.pdf [accessed 2021-09-27]

5. Beck MJ, Hensher DA. Insights into the impact of COVID-19 on household travel and activities in Australia - the early days of easing restrictions. Transp Policy (Oxf) 2020 Dec;99:95-119 [FREE Full text] [doi: 10.1016/j.tranpol.2020.08.004] [Medline: 32836998]

6. Torous J, Jän Myrick K, Rauseo-Ricupero N, Firth J. Digital mental health and COVID-19: using technology today to accelerate the curve on access and quality tomorrow. JMIR Ment Health 2020 Mar 26;7(3):e18848 [FREE Full text] [doi: 10.2196/18848] [Medline: 32213476]

7. Wahlund T, Mataix-Cols D, Olofsdotter Lauri K, de Schipper E, Ljótsson B, Aspvall K, et al. Brief online cognitive behavioural intervention for dysfunctional worry related to the COVID-19 pandemic: a randomised controlled trial. Psychother Psychosom 2021;90(3):191-199 [FREE Full text] [doi: 10.1159/000512843] [Medline: $\underline{33212440]}$

8. Covid-19-Pandemins Tänkbara Konsekvenser På Folkhälsan. Folkhälsomyndigheten. 2020 Jun 24. URL: https://tinyurl. com/3mbthdxc [accessed 2021-09-27]

9. Cuijpers P, de Wit L, Kleiboer A, Karyotaki E, Ebert DD. Problem-solving therapy for adult depression: an updated meta-analysis. Eur Psychiatry 2018 Feb 01;48(1):27-37. [doi: 10.1016/j.eurpsy.2017.11.006] [Medline: 29331596]

10. Wasserman D, Iosue M, Wuestefeld A, Carli V. Adaptation of evidence-based suicide prevention strategies during and after the COVID-19 pandemic. World Psychiatry 2020 Oct;19(3):294-306 [FREE Full text] [doi: 10.1002/wps.20801] [Medline: 32931107]

11. Detweiler Guarino I, Cowan DR, Fellows AM, Buckey JC. Use of a self-guided computerized cognitive behavioral tool during COVID-19: evaluation study. JMIR Form Res 2021 May 31;5(5):e26989 [FREE Full text] [doi: 10.2196/26989] [Medline: 33973856$]$

12. Hentati A, Forsell E, Ljótsson B, Kaldo V, Lindefors N, Kraepelien M. The effect of user interface on treatment engagement in a self-guided digital problem-solving intervention: A randomized controlled trial. Internet Interv 2021 Dec;26:100448 [FREE Full text] [doi: 10.1016/j.invent.2021.100448] [Medline: 34471610]

13. Hedman E, Ljótsson B, Kaldo V, Hesser H, El Alaoui S, Kraepelien M, et al. Effectiveness of Internet-based cognitive behaviour therapy for depression in routine psychiatric care. J Affect Disord 2014 Feb;155:49-58. [doi: 10.1016/j.jad.2013.10.023] [Medline: 24238951]

14. Kroenke K, Spitzer RL, Williams JBW. The Patient Health Questionnaire-2: validity of a two-item depression screener. Med Care 2003 Nov;41(11):1284-1292. [doi: 10.1097/01.MLR.0000093487.78664.3C] [Medline: 14583691]

15. Kroenke K, Spitzer RL, Williams JB, Monahan PO, Löwe B. Anxiety disorders in primary care: prevalence, impairment, comorbidity, and detection. Ann Intern Med 2007 Mar 06;146(5):317-325. [doi: 10.7326/0003-4819-146-5-200703060-00004] [Medline: 17339617$]$

16. Krippendorff K. Content Analysis: An Introduction to its Methodology. Thousand Oaks, CA: Sage Publications; 1980.

17. Schilling J. On the pragmatics of qualitative assessment. Eur J Psychol Assess 2006 Jan;22(1):28-37. [doi: $10.1027 / 1015-5759.22 .1 .28]$

18. McHugh ML. Interrater reliability: the kappa statistic. Biochem Med 2012:276-282. [doi: 10.11613/bm.2012.031]

19. Bick A, Blandin A, Mertens K. Work From Home After the COVID-19 Outbreak. Federal Reserve Bank of Dallas. 2020 Jun. URL: https://www.dallasfed.org/-/media/documents/research/papers/2020/wp2017.pdf [accessed 2021-09-27]

20. Fisher J, Languilaire J, Lawthom R, Nieuwenhuis R, Petts RJ, Runswick-Cole K, et al. Community, work, and family in times of COVID-19. Community Work Fam 2020 May 18;23(3):247-252. [doi: 10.1080/13668803.2020.1756568]

21. Galanti T, Guidetti G, Mazzei E, Zappalà S, Toscano F. Work from home during the COVID-19 outbreak: the impact on employees' remote work productivity, engagement, and stress. J Occup Environ Med 2021 Jul 01;63(7):e426-e432 [FREE Full text] [doi: 10.1097/JOM.0000000000002236] [Medline: 33883531]

22. Sheridan A, Andersen AL, Hansen ET, Johannesen N. Social distancing laws cause only small losses of economic activity during the COVID-19 pandemic in Scandinavia. Proc Natl Acad Sci U S A 2020 Aug 25;117(34):20468-20473 [FREE Full text] [doi: 10.1073/pnas.2010068117] [Medline: 32747573]

23. Arnold D, Milne A, Samms E, Stadon L, Maskell N, Hamilton F. Are vaccines safe in patients with long COVID? A prospective observational study. medRxiv Preprint posted online on March 14, 2021. [doi: 10.1101/2021.03.11.21253225] 
24. Brammer S, Branicki L, Linnenluecke MK. COVID-19, societalization, and the future of business in society. Acad Manag Perspect 2020 Nov;34(4):493-507. [doi: 10.5465/amp.2019.0053]

25. Nilsson A, Sörman K, Klingvall J, Ovelius E, Lundberg J, Hellner C. MyCompass in a Swedish context - lessons learned from the transfer of a self-guided intervention targeting mental health problems. BMC Psychiatry 2019 Jan 31;19(1):51 [FREE Full text] [doi: 10.1186/s12888-019-2039-1] [Medline: $\underline{30704424]}$

\section{Abbreviations \\ GAD-2: Generalized Anxiety Disorder-2 \\ PHQ-2: Patient Health Questionnaire-2}

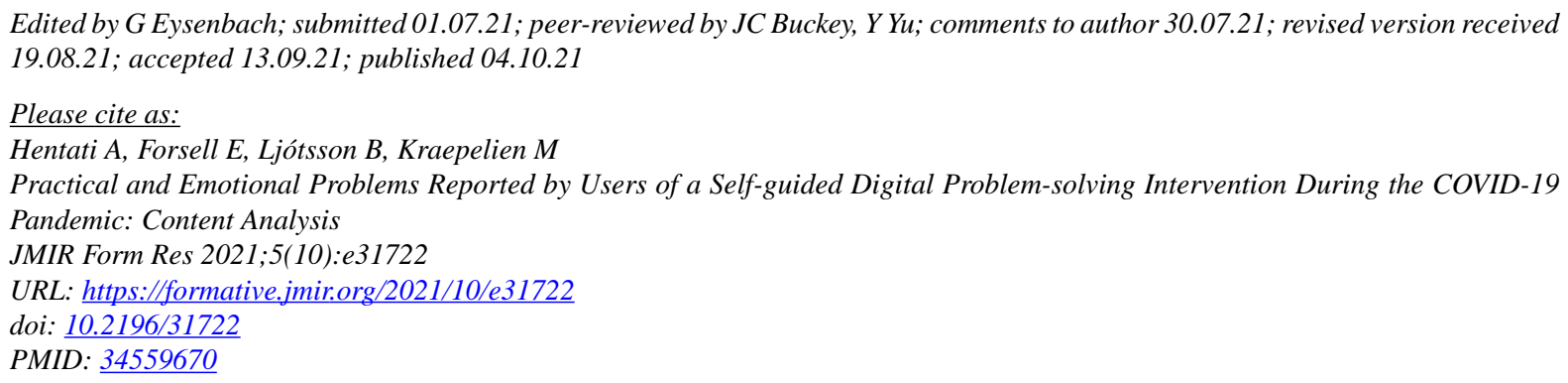

(C)Amira Hentati, Erik Forsell, Brjánn Ljótsson, Martin Kraepelien. Originally published in JMIR Formative Research (https://formative.jmir.org), 04.10.2021. This is an open-access article distributed under the terms of the Creative Commons Attribution License (https://creativecommons.org/licenses/by/4.0/), which permits unrestricted use, distribution, and reproduction in any medium, provided the original work, first published in JMIR Formative Research, is properly cited. The complete bibliographic information, a link to the original publication on https://formative.jmir.org, as well as this copyright and license information must be included. 